\title{
Crown Area as an Indicator of Changing Crown Size in Human Pre-natal Teeth
}

\author{
N. PRASAD ${ }^{1}$ and A.R. BURDI ${ }^{2}$ \\ The University of Michigan, Dental ${ }^{1}$ and Medical ${ }^{2}$ Schools, Ann Arbor, Michigan 48109
}

This study deals with correlations of tooth size in human primary teeth. Traditionally, mesiodistal or buccolingual measurements have been used to express crown size. However, in this study, crown area was used as a reference parameter.

Graphic reconstructions of 38 histologically prepared human fetuses with Crown-Rump Length (CRL) between 54 and $280 \mathrm{~mm}$ were used to obtain linear and area measurements. Based on clinical records and physical examinations, these fetuses were considered typical-for-age, or "normal". Correlation matrices indicated high levels of concordance among all developing deciduous tooth crowns and arch measurements. It was concluded that crown area is a statistically better trait to use in comparison of teeth rather than the traditional mesiodistal measurement.

J Dent Res 63(11):1302-1305, November, 1984

\section{Introduction.}

Tooth size is a determinant of normal development of occlusion in a child's dentition. The size of the maxillary and mandibular teeth must be in close harmony to permit proper interdigitation. Also, tooth size must be in harmony with arch size to permit proper alignment. The balance of tooth size and available arch size is often a prime consideration in many treatment and predictive approaches in interceptive orthodontics. A significant discrepancy between tooth size and available arch space has been identified as a leading etiological factor in crowding and spacing of erupted teeth (Lundstrom, 1954). Moorrees (1959) stated that marked differences in the relationship of deciduous and permanent teeth are particularly important in assessing the outcome of occlusal changes in the mixed dentition.

Tooth size has also been related to dental maturation. For example, the mandibular canines have the largest sex differences in the mesiodistal crown diameters, in the time required for their crown formation and in the ages at which emergence occurs (Moorrees, 1957).

Traditionally, mesiodistal or buccolingual measurements have been used to express crown size of teeth (Moorrees and Reed, 1954; Superstine, 1979; Doris et al., 1981). In using these parameters, moderate- or low-sized concordance patterns among teeth were observed (Moorrees and Reed, 1954; Doris et al., 1981). The present study hypothesizes that crown area is a better indicator of crown size than the traditional parameters, especially in pre-natal tooth development. This study concerns the relationships of the size of teeth, both individually and in groups, using crown area as a reference parameter. The degree of association was estimated by correlation coefficients.

\section{Materials and methods.}

This study is based upon two-dimensional graphic reconstructions derived from serially sectioned maxillofacial

Received for publication June 13, 1983

Accepted for publication August 10, 1984

This investigation was supported, in part, by USPHS Research Grant DE 03610 from the National Institute of Dental Research. regions taken from 38 human fetuses. The specimen pool ranged in gestation age from 10.5 weeks to 29 weeks, which corresponds to Crown-Rump Length (CRL) from 54 to 280 $\mathrm{mm}$. The sample consisted of 23 males and 15 females (22 white and 16 black fetuses).

The specimens were randomly chosen from a larger pool of fetuses from elective (induced) abortions. Thirty-eight of these fetuses were typical-for-age or "normal", in that they did not show any gross abnormalities. All specimens were fixed in $10 \%$ neutral buffered formalin. Graphic reconstructions were based on published procedures (Burdi, 1968; Garn et al., 1979) for two-dimensional graphic reconstructions of frontally-sectioned histologic tissues. Serial sections (from 10 to $15 \mu \mathrm{m}$ each) were stained with a Masson Trichrome connective tissue stain. Each serial section was then projected through a Leitz inverted microscope onto millimeter graph paper. Actual size of the finished graphic reconstruction was determined by the thickness of histological sections $(\mu \mathrm{m})$ and the number of frontal sections used multiplied by the microscopic enlargement factor as calibrated by a stage micrometer disc.

Measurements from the projected images were transferred via calipers to millimeter graph paper as perpendicular distances from the specimen's midline for proper orientation. For each projected section, the points on the sectioned tooth organ nearest and furthest from the midline were measured and transferred onto graph paper. This plotting procedure was used for multiple sections through each deciduous tooth crown or enamel organ. A line was then drawn connecting the nearest and furthest points seen in every section for a given tooth. When this was done for each of the five deciduous tooth crowns, the reconstruction showed the contour of each crown as well as the shape of the dental arch. All reconstructions and subsequent measurements were done by a single person (N.P.).

Measurements were taken directly from the arch-tooth graphic reconstructions. A polar planimeter was used to measure the area of each tooth crown. Repeated measurements were done of a known area to check the accuracy and replicability of the measurements. Correlation coefficients, analyses of variance, tests for covariance, paired $t$ tests, and pair-wise rank statistics were computed using the University of Michigan computer and MIDAS. Correlation matrices were also computed to test correlations between individual maxillary and mandibular teeth.

\section{Results.}

Initial tests for race and sex differences did not show significant differences in either crown size or arch area changes at a level of $p \leqslant 0.05$. Thus, data from the 38 "normal" fetuses were pooled. Hence, each of the following observations reflects a cross-sectional population profile of crown size-arch shape dimensions in human prenates from 10.5 to 29 weeks of age. Based on earlier observations of symmetrical development of teeth in right and left quadrants (MacConaill and Scher, 1949; Garn et al., 1970), only the right maxillary and mandibular jaw quadrants were analyzed in this study. 
TABLE 1

REGRESSION EQUATIONS FOR CHANGING CROWN SIZE

\begin{tabular}{|c|c|c|c|c|}
\hline Tooth & $54-150 \mathrm{~mm} / \mathrm{CRL}^{*}$ & $\mathrm{r}$ & $150-280 \mathrm{~mm} / \mathrm{CRL}^{* *}$ & $\mathrm{r}$ \\
\hline $\begin{array}{l}\mathrm{di}^{1} \\
\mathrm{di}^{2} \\
\mathrm{dc}^{1} \\
\mathrm{dm}^{1} \\
\mathrm{dm}^{2}\end{array}$ & $\begin{array}{l}y=1.9-0.56(X)+0.04(X)^{2} \\
y=1.7-0.47(X)+0.03(X)^{2} \\
y=1.2-0.34(X)+0.02(X)^{2} \\
y=6.94-1.9(X)+0.13(X)^{2} \\
y=2.13-0.57(X)+0.04(X)^{2}\end{array}$ & $\begin{array}{l}0.978 \\
0.896 \\
0.937 \\
0.957 \\
0.911\end{array}$ & $\begin{array}{l}-8.39+0.85(X) \\
-5.46+0.55(X) \\
-5.6+0.48(X) \\
-14.77+1.41(X) \\
-15.54+1.31(X)\end{array}$ & $\begin{array}{l}0.865 \\
0.725 \\
0.829 \\
0.838 \\
0.908\end{array}$ \\
\hline $\begin{array}{l}\mathrm{di}_{1} \\
\mathrm{di}_{2} \\
\mathrm{dc}_{1} \\
\mathrm{dm}_{1} \\
\mathrm{dm_{2 }}\end{array}$ & $\begin{array}{l}y=0.33-0.1(X)+0.01(X)^{2} \\
y=0.89-0.23(X)+0.02(X)^{2} \\
y=1.45-0.37(X)+0.02(X)^{2} \\
y=3.86-(X)+0.07(X)^{2} \\
y=1.7-0.44(X)+0.33(X)^{2}\end{array}$ & $\begin{array}{l}0.995 \\
0.980 \\
0.889 \\
0.955 \\
0.979\end{array}$ & $\begin{array}{r}-6.58+0.63(X) \\
-3.84+0.39(X) \\
-3.66+0.32(X) \\
-16.2+1.35(X) \\
-24.38+1.78(X)\end{array}$ & $\begin{array}{l}0.747 \\
0.734 \\
0.786 \\
0.851 \\
0.914\end{array}$ \\
\hline
\end{tabular}

*Formula $\mathrm{y}=\mathrm{a}+\mathrm{bx}+\mathrm{cx}^{2}$

**Formula $\mathrm{y}=\mathrm{a}+\mathrm{bx}$

Where $\mathrm{y}=$ area, $\mathrm{x}=\mathrm{CRL}$, superscripts indicate the maxilla and subscripts the mandible.

TABLE 2

CROWN SIZE CORRELATION MATRIX (I VALUES)*

\begin{tabular}{lllllllllllll}
\hline \hline $\mathrm{di}^{1}$ & 1.00 & & & & & & & & & \\
$\mathrm{di}^{2}$ & 0.97 & 1.00 & & & & & & & & \\
$\mathrm{dc}^{1}$ & 0.97 & 0.96 & 1.00 & & & & & & & \\
$\mathrm{dm}^{1}$ & 0.97 & 0.95 & 0.95 & 1.00 & & & & & & \\
$\mathrm{dm}^{2}$ & 0.98 & 0.95 & 0.96 & 0.97 & 1.00 & & & & & \\
$\mathrm{di}_{1}$ & 0.92 & 0.91 & 0.91 & 0.88 & 0.92 & 1.00 & & & & \\
$\mathrm{di}_{2}$ & 0.93 & 0.92 & 0.93 & 0.92 & 0.92 & 0.92 & 1.00 & & & \\
$\mathrm{dc}_{1}$ & 0.93 & 0.93 & 0.95 & 0.94 & 0.94 & 0.91 & 0.94 & 1.00 & & \\
$\mathrm{dm}_{1}$ & 0.93 & 0.92 & 0.92 & 0.97 & 0.95 & 0.88 & 0.90 & 0.95 & 1.00 & \\
$\mathrm{dm}_{2}$ & 0.94 & 0.93 & 0.92 & 0.95 & 0.97 & 0.87 & 0.87 & 0.93 & 0.97 & 1.00 \\
& $\mathrm{di}^{1}$ & $\mathrm{di}^{2}$ & $\mathrm{dc}^{2}$ & $\mathrm{dm}^{1}$ & $\mathrm{dm}^{2}$ & $\mathrm{di}_{1}$ & $\mathrm{di}_{2}$ & $\mathrm{dc}_{1}$ & $\mathrm{dm}_{1}$ & $\mathrm{dm}_{2}$ \\
\hline
\end{tabular}

Correlation between sum of maxillary teeth and sum of mandibular teeth $=0.98$.

${ }^{*} \mathrm{r}(0.05)=0.3246 ; \mathrm{r}(0.01)=0.4182$

Correlations between crown size (area) increases of primary maxillary and mandibular crowns in human prenates in the 10.5-29week gestational period.

Table 1 lists the best-fit equations to the changes in crown size or area for each of the five primary tooth crowns in the maxillary and mandibular jaw quadrants. In general, there is a relatively slow or curvilinear increase in crown area prior to $150 \mathrm{~mm} \mathrm{CRL}$, followed by a rapid or linear growth phase from 150 to $280 \mathrm{~mm} \mathrm{CRL}$. On a toothby-tooth basis, however, the rates and magnitudes of area changes in the reconstructed crowns vary. A comparison of central and lateral incisor areas shows that the maxillary incisors are uniformly larger than the mandibular incisors of the same individuals. The canine tooth areas for both the upper and lower jaw quadrants are relatively alike prior to $150 \mathrm{~mm}$ CRL, at approximately 17 weeks. A reconstruction of the growth curves for these canine teeth shows that the maxillary canine area becomes progressively larger after the 17-week period. Table 1 also shows that the sizes of the maxillary and mandibular molar crowns demonstrate the greatest increases in area in the shortest period of time. This is especially the case for the unerupted first molar crown, with the $\mathrm{dm}^{1}$ increases being greater than those for $\mathrm{dm}_{1}$. As a general pattern, it appears that crown area changes follow a curvilinear function up through $150 \mathrm{~mm}$ CRL, followed by a linear growth phase from $150 \mathrm{~mm} \mathrm{CRL} \mathrm{on.}$

Table 2 shows that crown area measurements are positively correlated with increases in fetal stature from 54 to $280 \mathrm{~mm}$ CRL. These correlations, as evident from the I values, are high and significant $(p \leqslant 0.01)$. The lowest $r$ value was 0.87 and the highest 0.98 . The $r$ values between the individual maxillary deciduous teeth all exceeded the 0.95 level. In the right mandibular arch quadrant, the $r$ values were somewhat lower. Correlations between the maxillary and mandibular tooth crowns were all above 0.91 , except for the crown area correlation between the mandibular central incisor $\left(\mathrm{di}_{1}\right)$ and the maxillary first molar $\left(\mathrm{dm}^{1}\right)$. The inference that can be drawn is that there is a highly correlated pattern of crown area or size among deciduous tooth crowns during gestation, and that crown area is a good indicator of crown size.

Table 3 shows that various dental arch measurements were also positively correlated in the $54-280-\mathrm{mm} \mathrm{CRL}$ period. The $I$ values were, again, high $(0.85-0.96)$ and significant $(p \leqslant 0.01)$. The $r$ values between the individual maxillary arch measurements were at or exceeded the 0.95 level, while they were somewhat lower in the mandibular quadrant $(\geqslant 0.85)$.

Figs. 1 and 2 show the field contributions of the anterior or incisor crowns and the posterior arch crowns (i.e., canine, first and second molars) to the total amount of tooth material in both the maxillary and mandibular arch quadrants studied. Fig. 1 shows that, during the 54-150-mm CRL period, the posterior maxillary crowns (c, dm 1 , and $\mathrm{dm} 2$ ) contributed only slightly more than did the anterior or incisor field to the sum total of crown areas. In other words, there was a greater anterior crown size during this pre-natal period. However, after the $150-\mathrm{mm}$ CRL period, or 17 weeks, the predominant contribution to the summed crown area was by the posterior three tooth crowns. Fig. 2 shows similar patterns of anterior and posterior crown size contributions to the total of crown areas in the mandibular arch quadrant. Also, in analyzing the size differences between the maxillary and mandibular incisor, canine and molar groups, individual or collective maxillary crown sizes were consistently greater than in the mandibular dental arch.

\section{Discussion.}

Traditionally, studies involving size of teeth have used either the mesiodistal or the buccolingual measurements as an indicator of crown size. In using these parameters, both in the pre- and the post-natal periods, the concordance pattern observed was only low-to-moderate. In other words, the degree of accuracy with which the sizes of other teeth could be predicted was only low-to-moderate. 
TABLE 3

DENTAL ARCH CORRELATION MATRIX (r VALUES)*

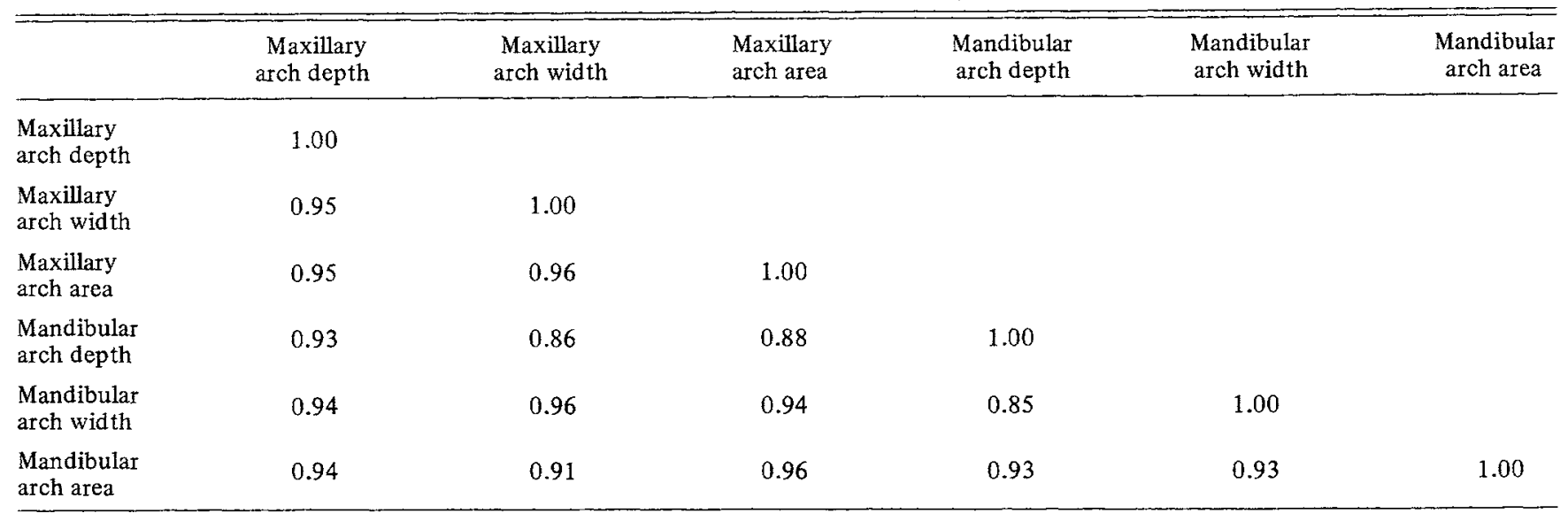

${ }^{*} \mathrm{r}(0.05)=0.3202 ; \mathrm{r}(0.01)=0.4128$

Correlations between arch size increases of maxillary and mandibular arches in human prenates in the 10.5-29-week gestational period.

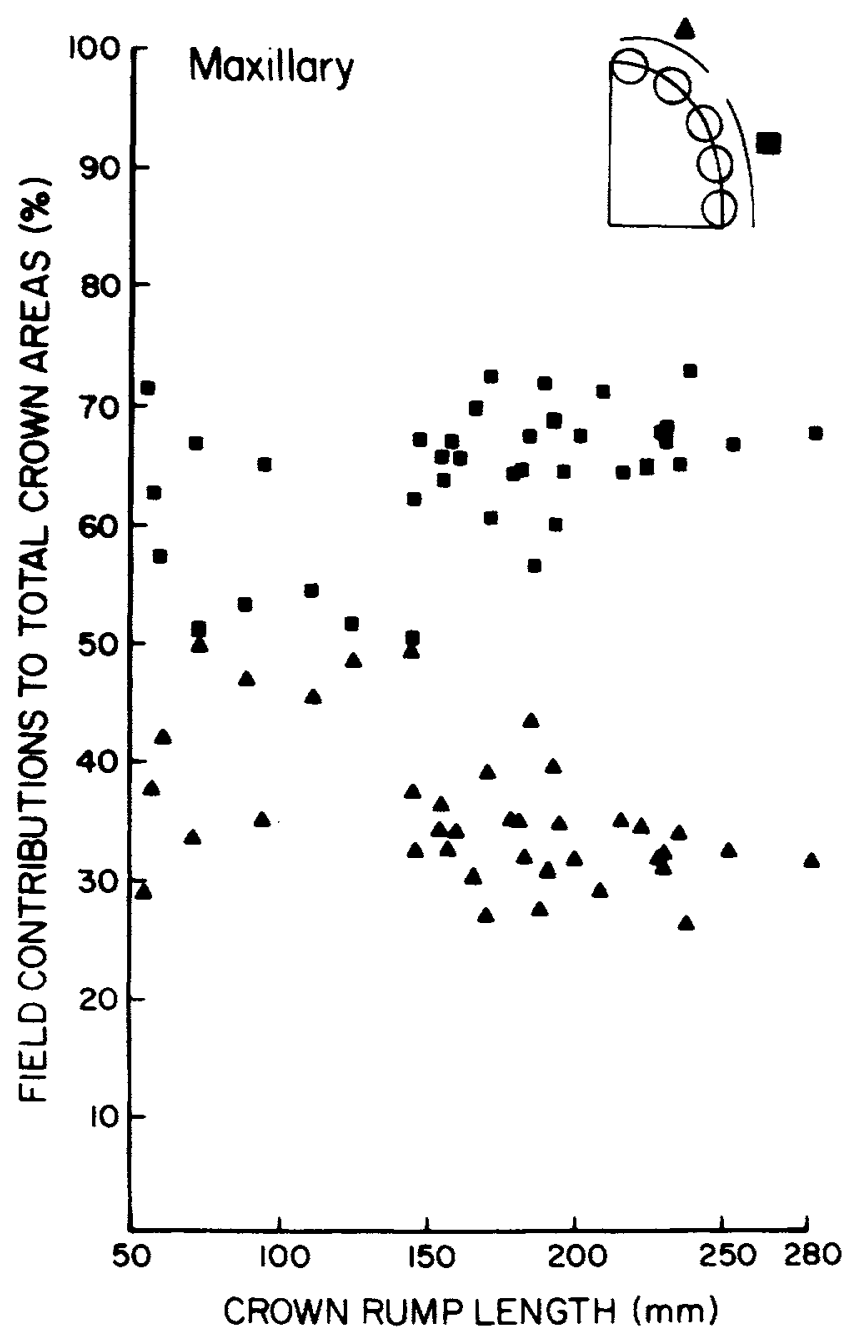

Fig. 1 - Fig. 1 shows the percentage contribution of summed crown areas of anterior (triangles) and posterior (squares) deciduous teeth to summed crown areas for each of the five maxillary deciduous crowns during the period of 10.5-29 gestational weeks.

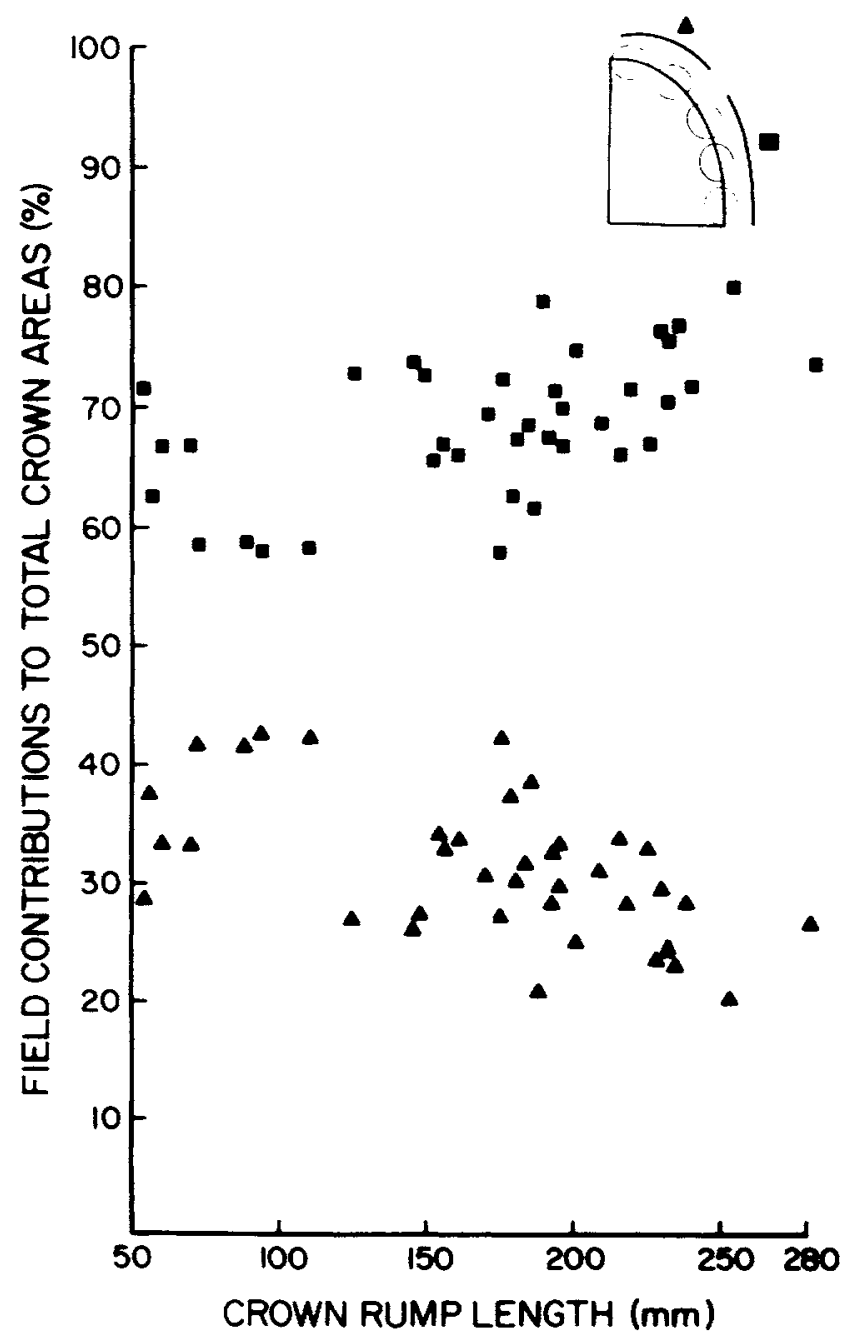

Fig. 2 - Fig. 2 shows the percentage contribution of summed crown areas of anterior (triangles) and posterior (squares) deciduous teeth to summed crown areas for each of the five mandibular deciduous crowns during the period of 10.5-29 gestational weeks. 
In the present study, crown area has been used as an indicator of crown size. Multiple correlations were computed using the crown area as a reference parameter. As seen in Table $1, \mathrm{r}$ values were very high and significant. The lowest $r$ value of 0.87 was observed between the mandibular primary central incisor and the mandibular primary second molar. An $r$ value of 0.97 was observed between a few teeth, both intra- and inter-arch. The inference drawn here is that, with a fairly high degree of accuracy, predictions can be made for the areas of other developing primary teeth when crown area is used as a reference parameter. The $r$ value between the sum of mandibular and maxillary teeth is 0.98 .

In comparing the arches themselves, a similarly high concordance pattern was observed (Table 2). Based on these observations, it is suggested that a genetic control mechanism operated early in the developmental process and was responsible for the synchronous pattern of development between the two jaws and between the individual primary teeth. Also, based on the high concordance pattern observed in this study, it is proposed that crown area measurements should be used as indicators of growth in crown size.

In studying the field contributions of the anterior (di1+ di2) and the posterior components $(d c+d m 1+d m 2)$, an interesting feature was noted. The anterior field showed a significantly higher contribution to the total field between the $54-150-\mathrm{mm}$ CRL period. This probably indicates that these teeth might be experiencing a "spurt" during this time frame, immediately followed by a greater increase of the posterior component. This pattern was similar in both the arches. The concept of anterior and posterior components is not a new one. Moyers' mixed dentition analysis utilizes this concept in predicting the availability of posterior space based on the measurements of the incisor teeth. This predictive approach is based on the observed correlations between the anterior and the posterior components. However, no observations have been made, so far, on the contributions of the anterior and the posterior components during the developmental period.

\section{REFERENCES}

BURDI, A.R. (1968): Morphogenesis of Mandibular Dental Arch Shape in Human Embryos, $J$ Dent Res 47:50-58.

DORIS, J.M.; BERNARD, B.W.; and KUFTINEC, M.M. (1981): A Biometric Study of Tooth Size and Dental Crowding, Am J Orthod 79:326-336.

GARN, S.M.; BURDI, A.R.; MILLER, R.L.; and NAGY, J.M. (1970): Prenatal Dental Development as a Reference Standard for Embryologic Status, $J$ Dent Res 49:894.

GARN, S.M.; BURDI, A.R.; BABLER, W.J.; and ASP, R. (1979): Crown Size-Arch Space Relationships during Human Prenatal Dental Development, $J$ Dent Res 58:554-559.

LUNDSTROM, A. (1954): Intermaxillary Tooth Width Ratio, Tooth Alignment and Occlusion, Acta Odontol Scand 12:265292.

MacCONAILL, M.A. and SCHER, E.A. (1949): The Ideal Form of Human Dental Arcade With Some Prosthetic Application, Dent $\operatorname{Rec}$ 69:285-302.

MOORREES, C.F.A. and REED, R.B. (1959): Biometrics of Crowding and Spacing of the Teeth in the Mandible, $A m J$ Phys $A n$ throp 12:77-78.

MOORREES, C.F.A.; THOMSEN, S.O.; JENSEN, E.; and YEN, P.K. (1957): Mesiodistal Crown Diameters of the Deciduous and Permanent Teeth in Individuals, $J$ Dent Res 36:39-47.

MOORREES, C.F.A. (1959): Dentition of the Growing Child, Cambridge: Harvard University Press.

MOYERS, R.E. (1975): Handbook of Orthodontics, 3rd ed. Chicago: Year Book Medical Publishers, Inc.

SUPERSTINE, J. (1979): Patterns of Early Human Dental Arch Morphogenesis: Biological and Clinical Relevances. Thesis. University of Michigan.

\title{
International Association for Dental Research \\ ORAL AND MAXILLOFACIAL SURGERY GROUP AWARD
}

\author{
Sponsored by Walter Lorenz \\ FOR JUNIOR INVESTIGATORS IN ORAL AND MAXILLOFACIAL SURGERY
}

First Annual Award

An award of $\$ 500$ (U.S. currency) and a plaque will be presented to the winning investigator at the annual Group meeting in March during the IADR General Session. The competition is open to those holding DDS, DMD, or Ph.D. degrees and having been engaged in post-doctoral training for no more than seven years. An abstract, after first being accepted for presentation at the IADR's 63rd General Session in March, 1985, should be submitted to reach Dr. Fred G. Emmings, University of Rochester, Strong Memorial Hospital, 601 Elmwood Avenue, Box 705, Rochester, New York 14642, on or before February 1, 1985. Only abstracts designated for the Oral and Maxillofacial Surgery Group are eligible. Both oral and poster presentations are eligible. All entrants must be sponsored by a member of the IADR or the Group. A plaque will also be presented to the sponsor. The awardee will be selected by the Group officers. 